\title{
Nebracetam Inhibited Hippocampus Neurons Injury Induced by A $\beta$ 25-35 in MRTF-A-CArG Manner via ERK1/2 Pathway
}

Tingzi Yin, Xiaolu Cao, Wan Xiao, Ying Zhang, Shuqi Zhao and Xiamin Hu*

Department of Pharmacology, Medical College of Wuhan University of Science and Technology, Huangjiahu Road Wuhan, PR China 430065

\begin{abstract}
Nebracetam has been recently proposed to have a neuroprotective action and cognitive enhancing effect being characteristic of a nootropic drug, while the mechanisms remained ambiguity. In this study, we investigated the protective effects of nebracetam on hippocampus neurons injury-induced by $\beta$-amyloid protein(A $\beta 25-35)$ and its mechanisms. Hippocampus neurons were treated with nebracetam $(0.05 \mathrm{mM}, 0.2 \mathrm{mM}$ or $0.8 \mathrm{mM})$ or A $25-35(20$ $\mathrm{uM} / \mathrm{L})$. We found that Nebracetam significantly reduced apoptotic induced by A $325-35$ and increase in the total number of dendritic spines and dendritic spine density in a dose-dependent manner. RT-PCR assay and Western blotting analysis revealed that nebracetam increased the expressions of myeloid cell leukemia-1 (Mcl-1), B-cell lymphoma-2 (Bcl-2) and activity regulated cytoskeleton associated protein (Arc) in Aß25-35-treated hippocampus neurons. Cotreatment nebracetam with MRTF-A (Myocardin-related transcription factor-A) siRNA reversed Mcl-1, Bcl-2 and Arc mRNA and protein levels. What's more, the luciferase assays indicated that the transcriptional activities of Mcl-1, Bcl-2 and Arc genes were significantly abolished by MRTF-A siRNA while it showed no changes on activities of mut Mcl1-promoter-luc, mut Bcl-2-promoter-luc and mut Arc-promoter-luc. Additionally, the up-regulation of $\mathrm{Mcl}-1, \mathrm{Bcl}-2$ and Arc protein expressions in nebracetam-treated group was inhibited by extracellular signal regulated protein kinase $1 / 2$ (ERK1/2) inhibitor PH98059. These results demonstrated that nebracetam inhibited A $325-35$-induced hippocampus neurons injury by enhancing the transactivity of $\mathrm{Mcl}-1, \mathrm{Bcl}-2$ and Arc, which may actively based in MRTF-A-CArGdependent manner by thwarting the ERK1/2 pathway.
\end{abstract}

Keywords: Nebracetam; Apoptosis; Synaptic plasticity; MRTF-A; ERK1/2 signaling pathway

\section{Introduction}

Nebracetam, 4-aminomethyl-1-benzylpyrrolidin-2-one, has been recently proposed to have a neuroprotective action and considered to improve the cognitive effect of nootropics [1]. Nebracetam enhances cholinergic neuro-transmission, and acts as a partial agonist presynaptically at muscarinic receptors. It also reduces dopaminergic and serotonergic uptake and inhibits intracellular calcium flux in response to glutaminergic stimulation [2]. Although the neuroprotection activity of nebracetam has been demonstrated, the mechanisms remained ambiguity.

Alzheimer disease (AD) is a neurodegenerative disease characterized by neuronal cell death, accumulation of extracellular amyloidplaques, neurofibrillary tangles (NTF) [3]. Various deranged mechanisms such as chronic oxidative stress [4], mitochondrial dysfunction $[5,6]$, A $\beta$ production [7], neurofibrillary tangles accumulation, hormone imbalance [8], inflammation, mitotic dysfunction [9], calcium mishandling [10], and genetic components [11] play a role in the disease process. Although the mechanisms are diverse, neuronal death, the inevitable event occurs resulting in $\mathrm{AD}$. Therefore, inhibiting neuronal apoptosis may be beneficial to prevent $\mathrm{AD}$. Bcl-2 family proteins are central regulators of apoptosis and consist of both anti-apoptotic and pro-apoptotic members based on their structure and function [12]. Mcl-1 (Myeloidcellleukemia-1) and Bcl-2 (B cell lymphoma/ leukemia-2) are the anti-apoptotic members, and increasing evidence has demonstrated that modifying neuronal synapses may play a major role in the pathophysiology of AD. The strategies to affect synaptic plasticity could have an enormous impact in improving outcomes of AD. The activity-regulated cytoskeletal (Arc) gene encodes a protein that is critical for memory consolidation [2]. Arc regulates synaptic strength through multiple mechanisms and is involved in essentially synaptic plasticity [13]. Studies of the transcriptional control of Bcl-2 and Mcl-1 expression have highlighted the regulation of MRTF-A on the CArG box in the promoters of Bcl-2 and Mcl-1 [14,15]. And we also found the CArG box in Arc promoter. Based on the importance of MRTF-A-mediated transcriptional regulation signal on apoptotic associated proteins, we speculated that MRTF-A and its target molecules might contribute to the protective effect of nebracetam on hippocampus neuron injury induced by $A \beta 25-35$. Furthermore, Luciferase report assay suggested that the CArG boxes in Mcl-1, Bcl-2 and Arc promoters were required for the transcriptional modulation of these target genes by nebracetam via MRTF-A-dependent mechanism. Therefore, it is conceivable that MRTF-A may mediate nebracetaminduced the modulation of neuronal Mcl-1, Bcl-2 and Arc expressions. Moreover, the activation of the ERK1/2 pathway might involve in the upregulatuion of Mcl-1, Bcl-2 and Arc expression and transcription activity in hippocampus neurons.

In this study, we found nebracetam inhibited A $\beta 25-35$-induced neuronal apoptosis and promoted neuronal synaptic plasticity, which is related to the up regulation of the mRNA and protein levels of Mcl$1, \mathrm{Bcl}-2$ and Arc. Furthermore, we speculated that MRTF-A is a key molecule in the up regulation of these target genes by nebracetam, while the ERK1/2 pathway was also involved.

\section{Materials and Method}

\section{Reagents}

Nebracetam was prepared in our laboratory (purity $\geq 98.77 \%$ ). Neurobasal ${ }^{\circ}$ - Medium and antibiotics were purchased from Gibco

*Corresponding author: Xiamin Hu, Department of Pharmacology, Medical College of Wuhan, University of Science and Technology, Wuhan, PR China, Tel: +86-27-68893283; Fax: +86-27-68759010; E-mail: huxiaming@163.com

Received December 30, 2015; Accepted January 02, 2016; Published January 11,2016

Citation: Yin T, Cao X, Xiao W, Zhang Y, Zhao S, et al. (2016) Nebracetam Inhibited Hippocampus Neurons Injury Induced by AB25-35 in MRTF-A-CArG Manner via ERK1/2 Pathway. Mol Biol 5: 152. doi:10.4172/2168-9547.1000152

Copyright: ( 2016 Yin T, et al. This is an open-access article distributed under the terms of the Creative Commons Attribution License, which permits unrestricted use, distribution, and reproduction in any medium, provided the original author and source are credited. 
Invitrogen (Carlsbad, CA, USA), and fetal bovine serum (FBS) was obtained from Hangzhou Sijiqing Biological Engineering Materials Co. Ltd (Hangzhou, China). Annexin V-FITC/PI cell apoptosis detection kit was purchased from Sigma Chemical Co. (St. Louis, MO). Mouse monoclonal antibodies against M2F6, Mcl-1, Bcl-2, Arc and $\beta$-actin were obtained from Santa Cruz Biotechnology (Santa Cruz, CA, USA). Trizol Reagent was purchased from Invitrogen. RevertAid First strand cDNA synthesis kit was from Thermo scientific. Other general agents were available commercially.

\section{Cell culture}

Rat hippocampus neurons were dissociated from the rats born in $24 \mathrm{~h}$ and cultured at a density of $1.5 \times 10^{5} \mathrm{cells} / \mathrm{cm}^{2}$ onto poly-D-lysinecoated 96- or 6-well plates, or cover slips. The cells were cultured in Neurobasal ${ }^{\circ}$ - Medium with $15 \%$ horse serum, $2.5 \%$ fetal bovine serum, $100 \mathrm{U} / \mathrm{ml}$ penicillin, $100 \mu \mathrm{g} / \mathrm{ml}$ streptomycin, and were maintained in a humidified incubator in air with $5 \% \mathrm{CO}_{2}$. For this study, the cells were pretreated with vehicle (PBS), nebracetam (freshly made) at different dosage $(0.05 \mathrm{mM}, 0.2 \mathrm{mM}$ or $0.8 \mathrm{mM})$ for $24 \mathrm{~h}$ and then exposed to A $325-35$ for another $24 \mathrm{~h}$.

\section{Apoptosis analysis by flow cytometry}

Detection of apoptosis by flow cytometry was performed using the AnnexinV-FITC/PI apoptosis detection kit. After preincubated with nebracetam $(0.05 \mathrm{mM}, 0.2 \mathrm{mM}$ or $0.8 \mathrm{mM})$ for $24 \mathrm{~h}$, and exposured with $\mathrm{A} \beta 25-35(20 \mathrm{uM} / \mathrm{L})$ for $24 \mathrm{~h}$, cells cultured on 6 -well plates were washed twice with ice-cold phosphate buffered saline (PBS), suspended in PBS, followed by centrifugating at $1200 \mathrm{rpm}$ for $5 \mathrm{~min}$. After discarding the supernatant, the cells were resuspended in $200 \mu \mathrm{L}$ binding buffer and incubated with $10 \mu \mathrm{L}$ Annexin V-FITC and $10 \mu \mathrm{L}$ PI at room temperature for $15 \mathrm{~min}$ in the dark. Then the cells were added 300ul binding buffer before the fluorescence analysis was performed using a flow cytometer [16] (BD-LSRII, U.S.A.).

\section{Synaptic morphological analysis}

Hippocampus neurons were fixed with $4 \%$ Paraformaldehyde and rinsed extensively in PBS, and then exposed for $2 \mathrm{~h}$ at room temperature to the drebrin (M2F6) mouse monoclonal antibody at a concentration of 1:200. Following the PBS rinses, covers lips were incubated for $1 \mathrm{~h}$ at room temperature with the secondary antibody. Wash Five times for 5 min with $2 \mathrm{ml}$ of PBS. Mount slide with anti-fading agent. Images were acquired using a confocal laser scanning unit [17].

\section{Reverse-transcription PCR (RT-PCR) assay}

Total RNA was isolated from hippocampus neurons using Trizol Reagent (Invitrogen, U.S.A.) according to the manufacturer's protocol. Aliquots $(2 \mu \mathrm{g})$ of total RNA were reverse-transcribed into cDNA by using oligo-dT as a primer in $20 \mu \mathrm{L}$ reverse-transcription solution and amplified by a thermal cycler (Bio-Rad, CA). Complementary DNA was then used as a template for PCR carried out in $18 \mu \mathrm{L}$ reaction mixture containing $0.6 \mu \mathrm{L}$ of each primer, 1.8 $\mu \mathrm{L}$ 10X Taq Buffer, and $0.11 \mu \mathrm{L}$ of Taq polymerase (Takara, Japan). Primers sequences were designed using primer 5.0 as follows: $\beta$-actin forward: 5 -GAGGGAAATCGTGCGTGAC-3'; $\beta$-actin reverse: 5'-CTGGAAGGTGGACAGTGAG-3'; Mcl-1 forward: 5'TCATCTCCCGCTACCT.

GC-3'; Mcl-1 reverse: 5'-ACTCCACAAACCCATCCC-3'; Bcl-2 forward: 5'-GGCATCTTCTCCTTCCAG-3'; Bcl2 reverse: 5'-CATCCCAGCCTCCGTTAT-3'; Arc forward: 5'-TGAGGAGGAGGAGATCATTC-3'; Arc reverse: 5'-TACTGACTCG
CTGGTAAGAG-3'. The PCR reaction was conducted for 35 cycles and each cycle consisted of $30 \mathrm{~s}$ of denaturing at $94^{\circ} \mathrm{C}, 30 \mathrm{~s}$ of annealing at $54^{\circ} \mathrm{C}\left(\beta\right.$-actin), $53.2^{\circ} \mathrm{C}(\mathrm{Mcl}-1), 56.2^{\circ} \mathrm{C}(\mathrm{Bcl}-2), 54^{\circ} \mathrm{C}(\mathrm{Arc})$ and $60 \mathrm{~s}$ of elongation at $72^{\circ} \mathrm{C}$. The PCR conditions for the analysis of the expression of each gene were designed to avoid saturation and enable a semi-quantitative determination. The amplicons were resolved by electrophoresis on $1.2 \%$ agarose gels and visualized with Glodview staining by GENE GENIUS system (Syngene, U.S.A.). Each sample was run in duplicate and was controlized against the data for-actin, averaged, and statistically compared. The relative density of the immunoreactive bands was quantitatived by Quantity One (Version 4.6.2, Bio-Rad Technical Service Department, USA).

\section{Western blotting analysis}

The cells were washed twice with cold PBS before lysed in ProteoJET ${ }^{\mathrm{m}}$ Mammalian Cell Lysis Reagent (MBI Fermentas). The lysate was centrifugated at $4^{\circ} \mathrm{C}, 16000 \mathrm{rpm}$ for $45 \mathrm{~min}$. Equal amounts of proteins were subjected to electrophoresis on $4.12 \%$ Bis-Tris NuPAGE Mini-gel (Invitrogen), followed by transfer to PVDF membrane (Millipore).The membrane was blocked with $5 \%$ non-fat milk for $1 \mathrm{~h}$ and incubated with primary antibody overnight at $4^{\circ} \mathrm{C}$. After incubation with secondary conjugated antibody for $1 \mathrm{~h}$, the membrane was subjected to enhanced chemiluminescence detection using SuperSignal West Pico Chemiluminescent Substrate (Pierce). The protein expression levels were quantified by the Adobe Photoshop software.

\section{Luciferase reporter assay}

The promoter-linked luciferase reporters including Mcl-1, Bcl-2, Arc CArG or their mutants $(0.5 \mu \mathrm{g})$ were transiently transfected with 1ng CMV-Renilla Luciferase reporter (Promega) into hippocampus neurons using the Lipofectamine and Plus transfection reagents (Invitrogen) for $24 \mathrm{~h}$. The promoter activities were determined by the firefly luciferase activity relative to the internal control renilla luciferase activity using the dual luciferase assay system described by the manufacturer (Promega, Madison, WI).

\section{Statistical analysis}

Experiments were repeated three times and the results were statistically evaluated with SPSS11.software. Hypothesis testing methods included one way analysis of variance (ANOVA) followed by least significant difference (LSD) test; $p$ value of less than 0.05 were considered to indicate statistical significance. All the results were expressed as the mean \pm S.D.

\section{Results}

Nebracetam inhibited apoptosis in neuronal hippocampus induced by $A \beta 25-35$ and reduced $A \beta 25-35$ induced hippocampus neuronal synaptic injury in vitro

The primary hippocampus neurons were pretreated with different dosages of nebracetam $(0.05 \mathrm{mM}, 0.2 \mathrm{mM}$ and $0.8 \mathrm{mM})$ for $24 \mathrm{~h}$. and then, the cells were exposed to A $325-35$ for another $24 \mathrm{~h}$. The apoptotic rate was determined by flow cytometry analysis. The results (Figure 1A) showed that pre-treated with nebracetam significantly decreased the apoptosis rate at the concentration of $0.2 \mathrm{mM}$ (apoptotic rate: 16 $\pm 1.5 \%,{ }^{* *} \mathrm{p}<0.01$ ) and $0.8 \mathrm{mM}$ (apoptotic rate: $8.4 \pm 1.4 \%,{ }^{* *} \mathrm{p}<0.01$ ) compared to $A \beta 25-35$-treated group (apoptotic rate: $39 \pm 2.9 \%$ ) in primary hippocampus neurons culture in a dose-dependent manner (Figure 1A).

Drebrin is an actin-binding protein expressing mainly in neurons [18], 

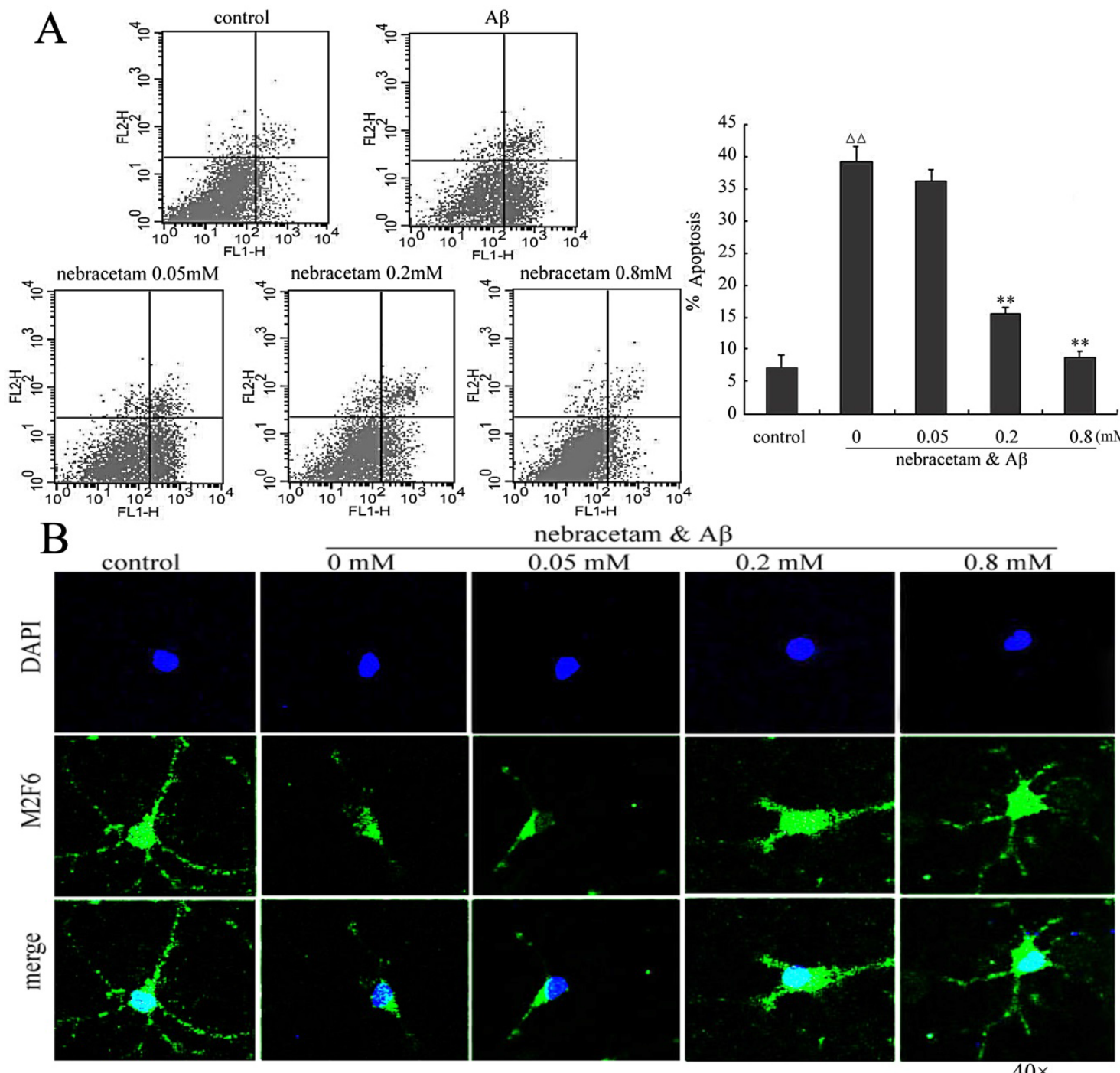

$40 \times$

Figure 1: Effect of Nebracetam on hippocampus neuronal apoptosis and synaptic injury induced by $A \beta_{25-35}$ in vitro. (A) Hippocampus neuronal apoptosis was determined by flow cytometry using the Annexin V-FITC/PI apoptosis detection kit. (B) Hippocampus neuronal dendritic spine was performed by the laser confocal scanning microscopy (40X). Results are presented as means \pm S.D (n=5). ${ }^{\Delta} p<0.05,{ }^{\Delta} p<0.01$ vs. control, ${ }^{*} p<0.05,{ }^{* *} p<0.01$ vs. A $\beta_{25-35}$-treated group.

and play a role in the structure-based plasticity [19]. The antibody M2F6 reacts with both the embryonic (drebrinE) and adult (drebrinA) isoforms of drebrin [20]. Confocal images showed that a significant degeneration of dendritic spines was observed in $\mathrm{A} \beta 25-35$ treated group (Figure 1B). However, nebracetam significantly increased the number of dendritic spine and the density of dendritic spine in hippocampus neurons at the concentration of $0.2 \mathrm{mM}$ or $0.8 \mathrm{mM}$ for $24 \mathrm{~h}$ in a dose-dependent manner.

\section{Nebracetam upregulated the mRNA and protein levels of Mcl-1, Bcl-2 and Arc}

The data (Figure 2) showed that pre-treated with A $325-35$ significantly decreased the mRNA and protein levels of Mcl-1, Bcl2 and Arc in hippocampus neurons. However, preincubation with nebracetam obviously upregulated the mRNA and protein levels of Mcl$1, \mathrm{Bcl}-2$ and Arc at the concentration of $0.2 \mathrm{mM}$ or $0.8 \mathrm{mM}\left({ }^{*} \mathrm{p}<0.05\right.$ or $\left.{ }^{* *} \mathrm{p}<0.01\right)$ compared to $A \beta 25-35$-treated group, which suggested that the neuroprotective effect of nebracetam against neuronal apoptosis might be associated with its upregulation the mRNA and protein expressions of Mcl-1, Bcl-2 and Arc.
MRTF-A involved in Nebracetam inhibiting A $\beta 25-35$ induced hippocampus neuronal apoptosis and reducing $\mathrm{A} \beta 25-35$ induced hippocampus neuronal synaptic injure in vitro

Our previous study [17] has shown that MRTF-A, as a cotranscription factory of SRF, plays an important role in promoting neuronal survival against apoptosis, which is dependent on the binding of SRF and CArG boxes located on anti-apoptosis related gene (such as Mcl-1 and Bcl-2). To determine the exact role of MRTF-A in the effect of nebracetam on $A \beta 25$-35-induced hippocampus neuron apoptosis, we knocked down hippocampus neuronal MRTF-A using MRTF-A siRNAs. Interestingly, we found that the inhibition of nebracetam on neuronal apoptosis was also reduced markedly by MRTF-A siRNA (Figure 3A). We next explored whether MRTF-A also participated in the effect of nebracetam on hippocampus neuronal synapse. Confocal laser scanning was used to observe the changes in dendritic spines of hippocampus neuron. As expect, preincubation with nebracetam significantly increased in the number and the density of dendritic spine in hippocampus neurons. However, the protect effects of nebracetam 
A
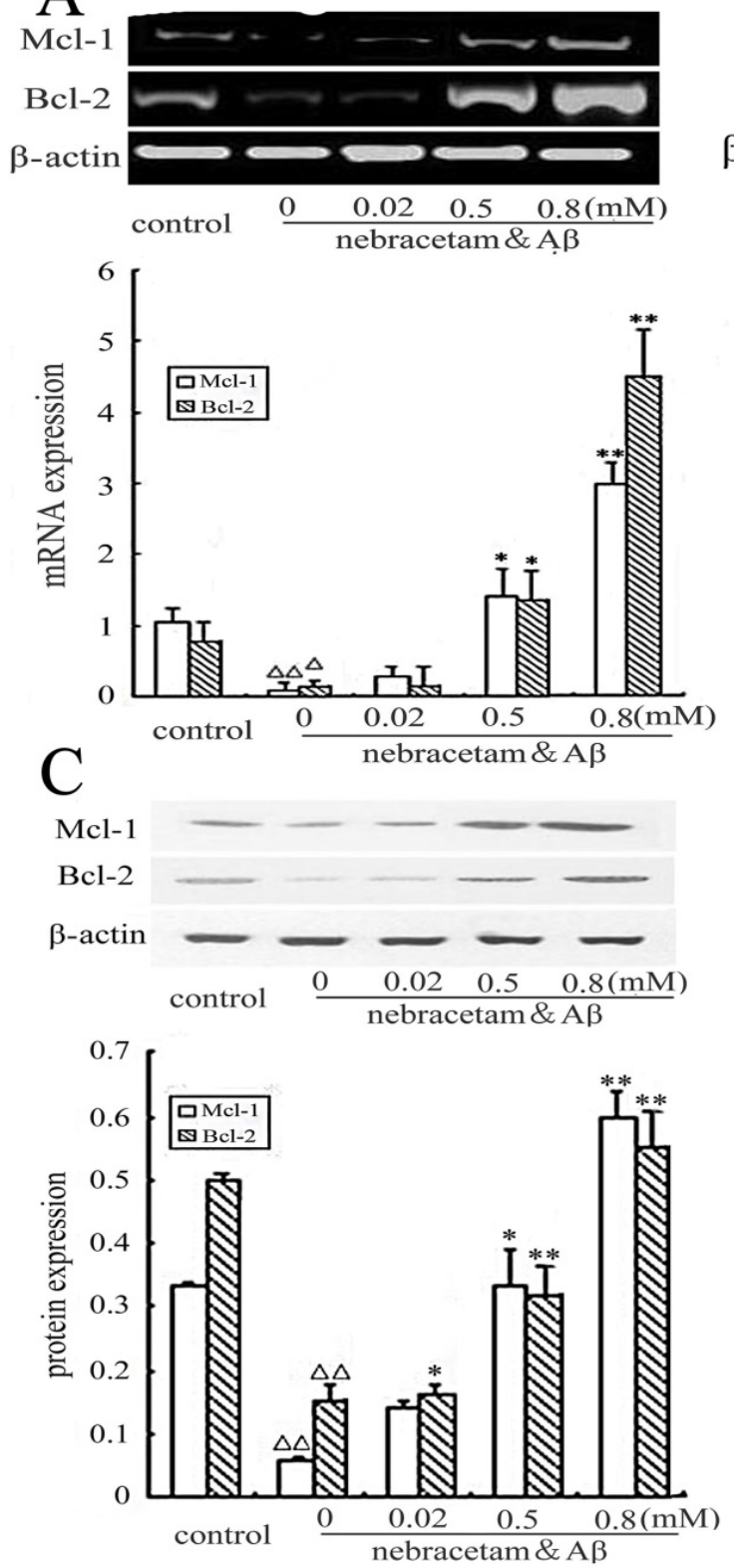

B

Arc

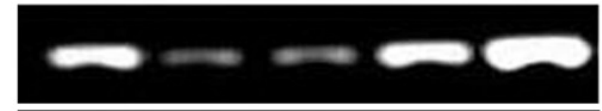

$\beta$-actin

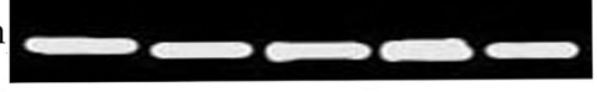

control $\frac{0}{0.02 \quad 0.5 \quad 0.8(\mathrm{mM})}$

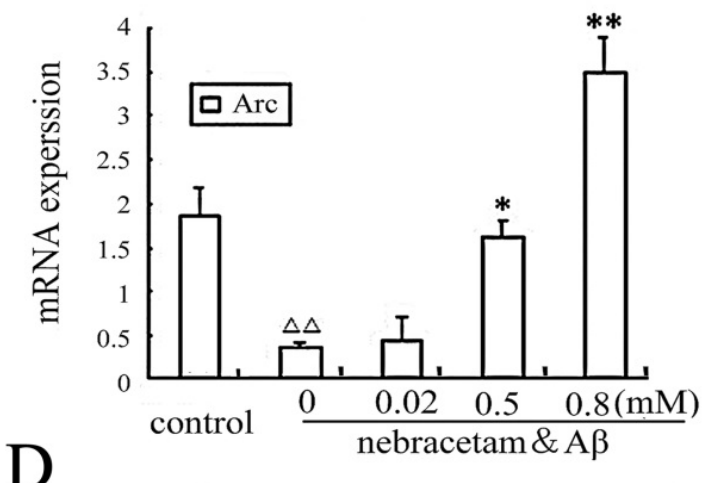

$\mathrm{D}$
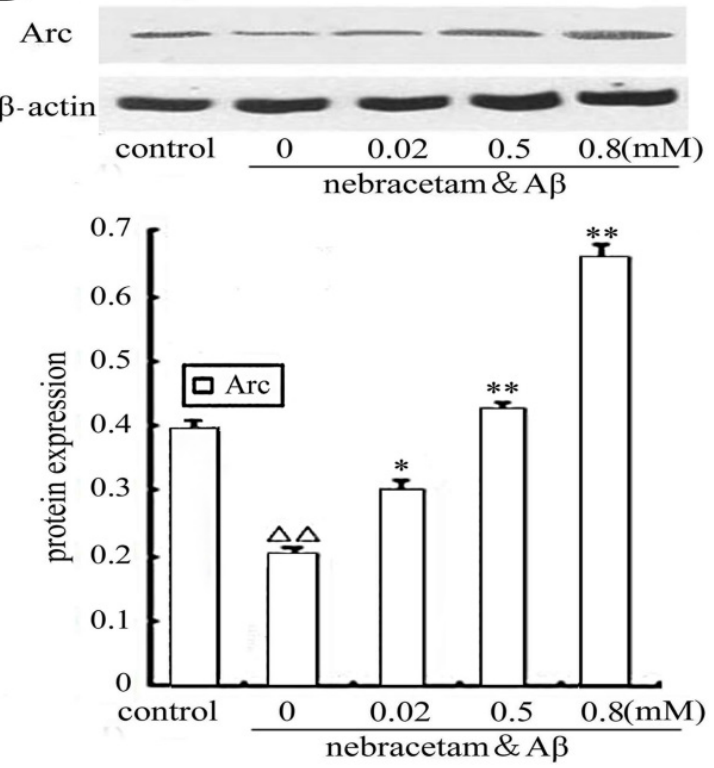

Figure 2: Nebracetam upregulating the mRNA and protein levels of $\mathrm{Mcl}-1, \mathrm{Bcl}-2$ and Arc genes in primary hippocampus neurons. (A, B) RT-PCR assays for the mRNA levels of Mcl-1, Bcl-2 and Arc in hippocampus neurons. (C, D) Western Blot assays for the protein expressions of Mcl-1, Bcl-2 and Arc in hippocampus neurons. Results are presented as means \pm S.D $(n=3) .{ }^{\Delta} p<0.05,{ }^{\Delta \Delta} p<0.01$ vs. control, ${ }^{*} p<0.05,{ }^{*} p<0.01 v s . A \beta_{25-35}$ treated group.

on synaptic injury was markedly weaked by MRTF-A siRNA in a dosedependent manner (Figure 3B).

\section{Nebracetam upregulating the transactivity and expression of} Mcl-1, Bcl-2 and Arc via a MRTF-A-dependent mechanism

Based on the above results, we next explored whether MRTF-A also participated in the regulation of nebracetam on Bcl-2, Mcl-1 and Arc levels. Extensive studies have been carried out to characterize the molecular mechanism of MRTF-A regulates Mcl-1, Bcl-2 and Arc expression [17]. As expect, the increasing of Bcl-2, Mcl-1 and Arc mRNA and protein levels induced by nebracetam was weakened when cotransfected with MRTF-A siRNA (Figure 4).

Next, we hypothesized that the effect of nebracetam enhancing the expressions of Bcl-2, Mcl-1 and Arc via MRTF-A mediated transcription mechanism. To test this hypothesis, we investigated the transactivity of Bcl-2, Mcl-1 and Arc promoters in primary hippocampus neurons after treated with nebracetam alone or cotransfected with MRTF-A siRNA. The transient luciferase assays showed that nebracetam activated the luciferase gene expressions driven by WT Bcl-2, Mcl-1 and Arc promoters dose-dependently, whereas this effects was significantly repressed by cotransfection with MRTF-A siRNA in a dose dependent manner (Figures 5C and 5D).

To determine whether the transactivation of Bcl-2, Mcl-1 and Arc promoters induced by nebracetam is dependent on the CArG box, we constructed the dominant negative luciferase reporter vectors of Bcl-2, Mcl-1 and Arc gene promoter (mut-Bcl-2 luc, mut-Mcl-1 luc and mut- 
Citation: Yin T, Cao X, Xiao W, Zhang Y, Zhao S, et al. (2016) Nebracetam Inhibited Hippocampus Neurons Injury Induced by A $325-35$ in MRTF-ACArG Manner via ERK1/2 Pathway. Mol Biol 5: 152. doi:10.4172/2168-9547.1000152
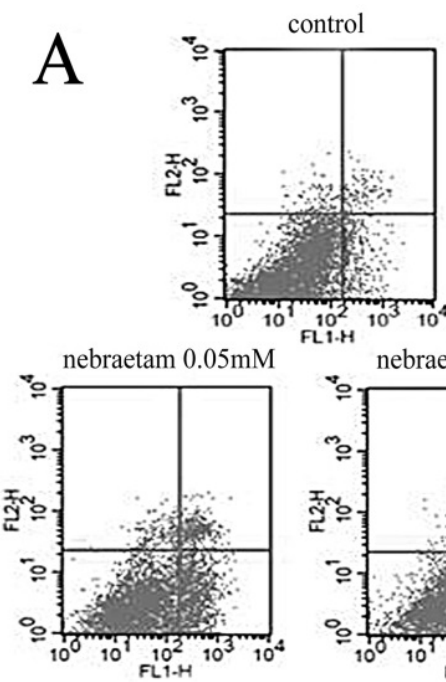

nebraetam $0.05 \mathrm{mM} \&$ MRTF-A siRNA $0.5 \mu \mathrm{g}$
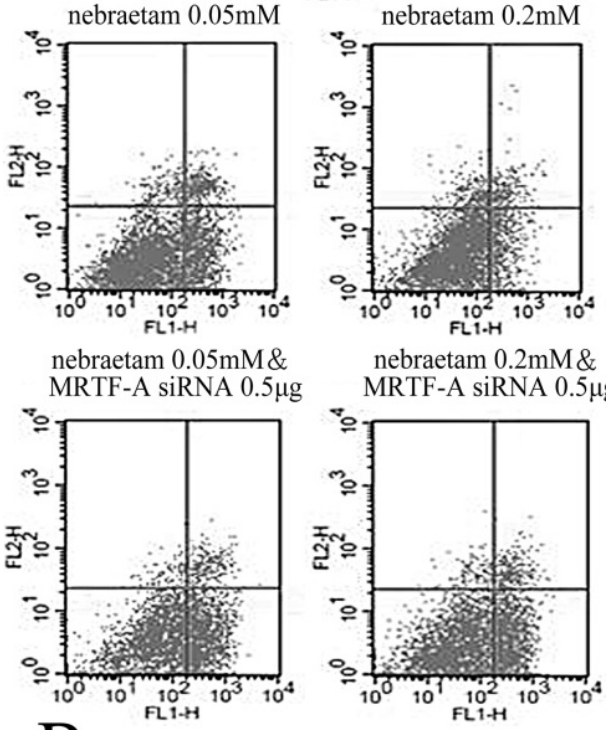

nebraetam $0.2 \mathrm{mM} \&$ MRTF-A SIRNA $0.5 \mu \mathrm{g}$

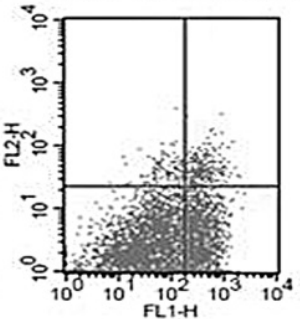

B
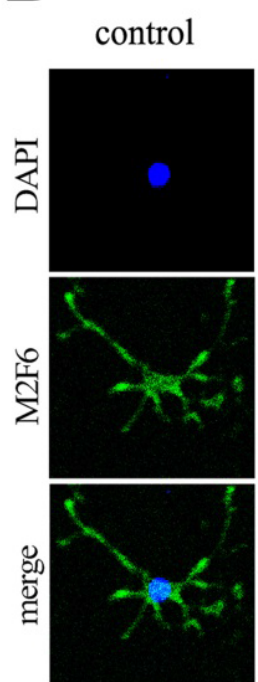

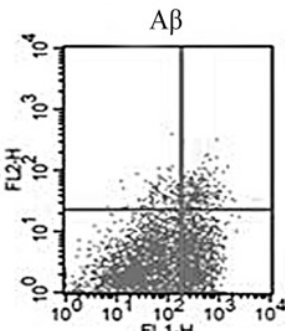

nebraetam $0.8 \mathrm{mM}$

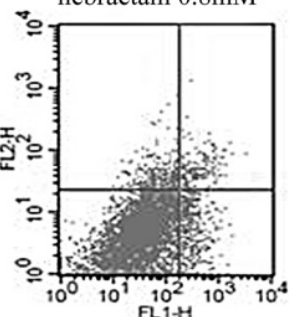

nebraetam $0.8 \mathrm{mM} \&$ MRTF-A siRNA $0.5 \mu$

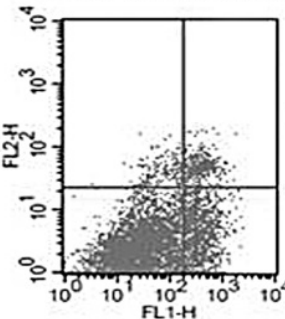

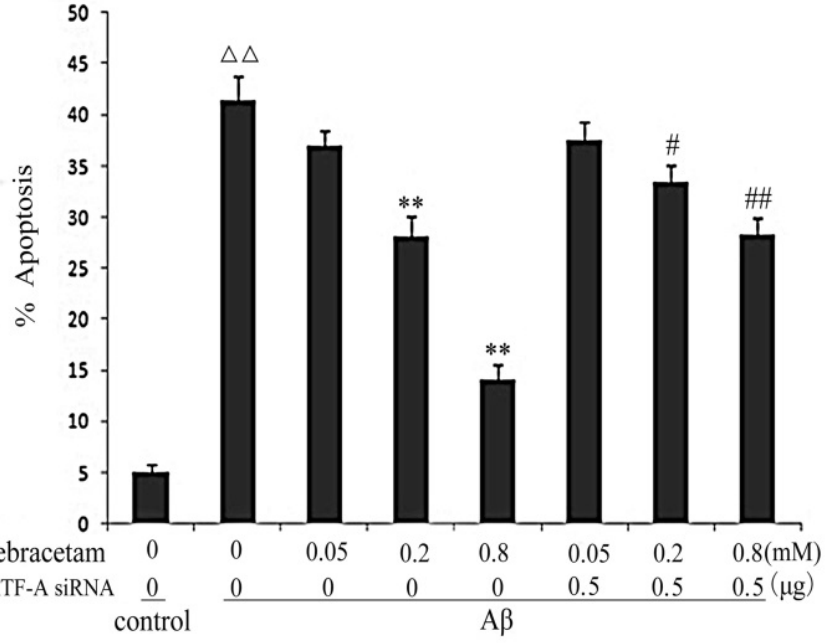

nebracetam

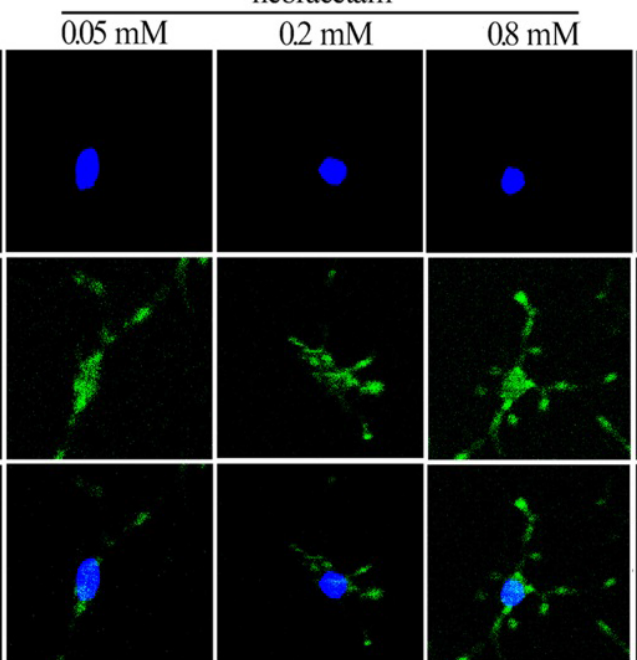

nebracetam \& MRTF-A siRNA $(0.5 \mu \mathrm{g})$

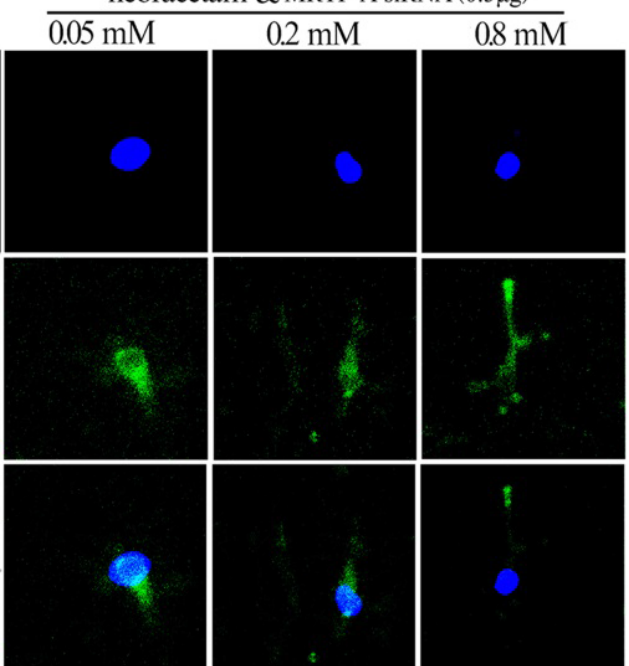

$40 \times$

Figure 3: Nebracetam inhibited hippocampus neuronal apoptosis and synaptic injury involved MRTF-A. (A) The apoptotic of co-treatment nebracetam with MRTF-A siRNA on primary hippocampus neurons was determined by flow cytometry. (B) Morphology of hippocampus neurons treated with nebracetam and MRTF-A siRNA by immunofluorescence assay (40X). Results are presented as means \pm S.D $(n=3)$. ${ }^{\Delta} p<0.05$ or ${ }^{\Delta \Delta} p<0.01$ vs. Control, ${ }^{*} p<0.05$ or ${ }^{* *} p<0.01$ vs. model. ${ }^{\#} p<0.05$ or ${ }^{\#} p<0.01$

$v s$. the same dosage of nebracetam without MRTF-A siRNA groups, respectively.

Arc luc, respectively ). Our dates showed that the nebracetam induced transactivation of Bcl-2, Mcl-1 and Arc promoters was reduced or abolished after the mutation of the CArG boxes in Bcl-2, Mcl-1 and Arc promoters (Figures $5 \mathrm{E}$ and $5 \mathrm{~F}$ ), suggesting that nebracetam induced transactivation of Bcl-2, Mcl-1 and Arc promoters through activating the key CArG box, which was the transcriptional regulatory element transactivated by MRTF-A.

\section{ERK-dependent pathways involved in the effect of Nebracetam on MRTF-A induction.}

To determine whether the anti-apoptotic effect of nebracetam was associated with ERK pathway, Cells were treated with PD98059 (the inhibitor for ERK1/2 signal pathway) to inhibit ERK pathway in A 325 35-treated hippocampus neurons after pretreated with nebracetam. 
Citation: Yin T, Cao X, Xiao W, Zhang Y, Zhao S, et al. (2016) Nebracetam Inhibited Hippocampus Neurons Injury Induced by A $325-35$ in MRTF-ACArG Manner via ERK1/2 Pathway. Mol Biol 5: 152. doi:10.4172/2168-9547.1000152

A

Mcl-1

$\mathrm{Bcl}-2$

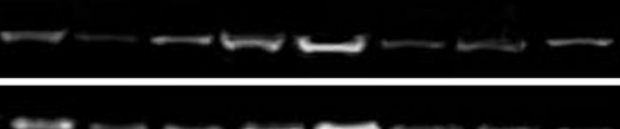

$\beta$-actin

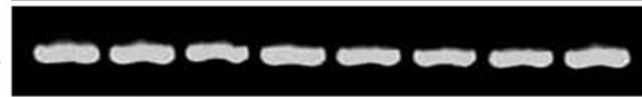

$\begin{array}{lllllllll}\text { nebracetam } & 0 & 0 & 0.05 & 0.2 & 0.8 & 0.05 & 0.2 & 0.8(\mathrm{mM})\end{array}$ \begin{tabular}{llllllll} 
MRTF-A siRNA $\underline{0} \quad \underline{0}$ & 0 & 0 & 0 & 0.5 & 0.5 & 0.5 \\
\hline
\end{tabular} control

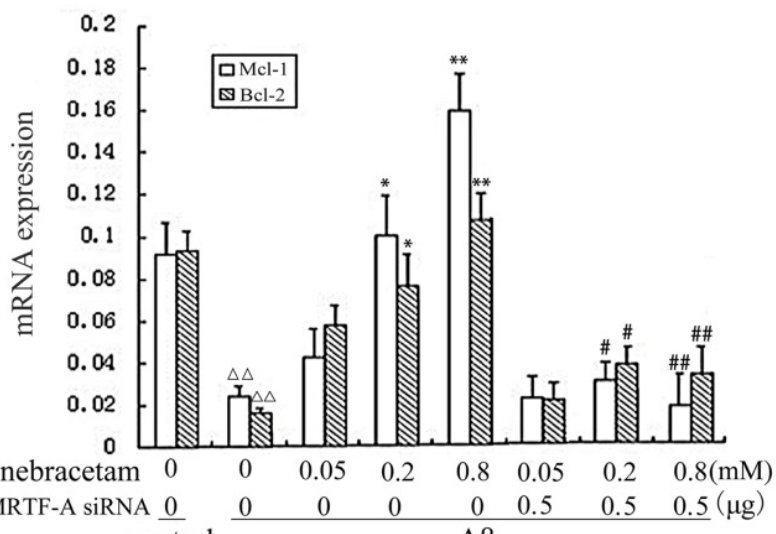

$\mathrm{C}$

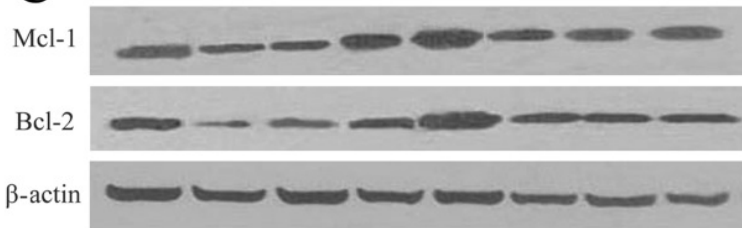

$\begin{array}{lllllllll}\text { nebracetam } & 0 & 0 & 0.05 & 0.2 & 0.8 & 0.05 & 0.2 & 0.8(\mathrm{mM})\end{array}$ $\begin{array}{llllllll}\text { MRTF-A siRNA } \underline{0} \quad \underline{0} & 0 & 0 & 0 & 0.5 & 0.5 & 0.5\end{array}(\mu \mathrm{g})$ control

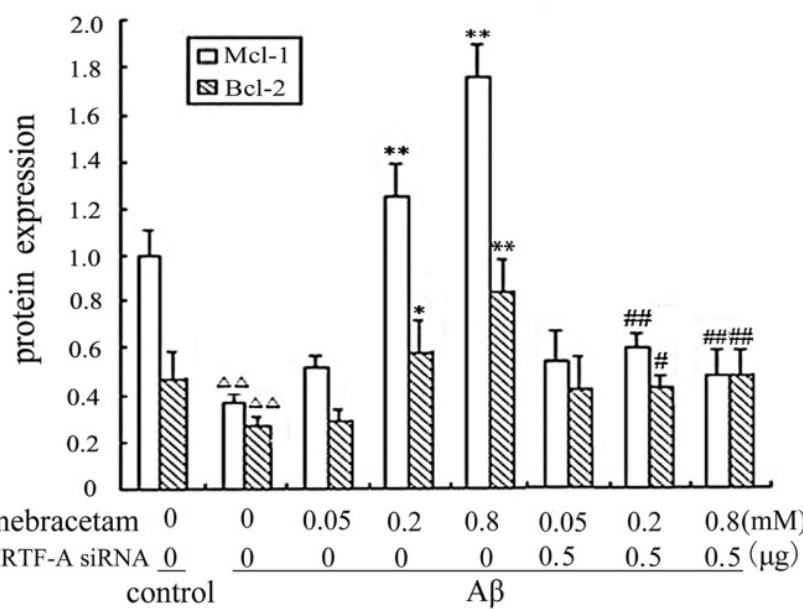

B

Arc

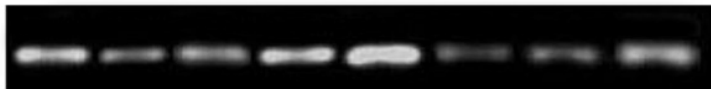

$\beta$-actin

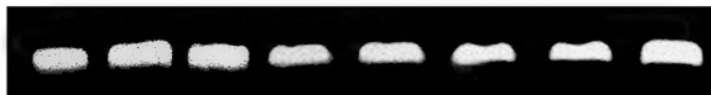

$\begin{array}{lllllllll}\text { nebracetam } & 0 & 0 & 0.05 & 0.2 & 0.8 & 0.05 & 0.2 & 0.8(\mathrm{mM})\end{array}$

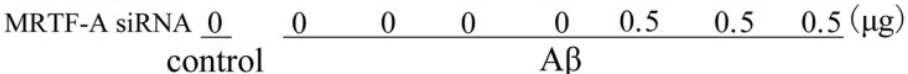

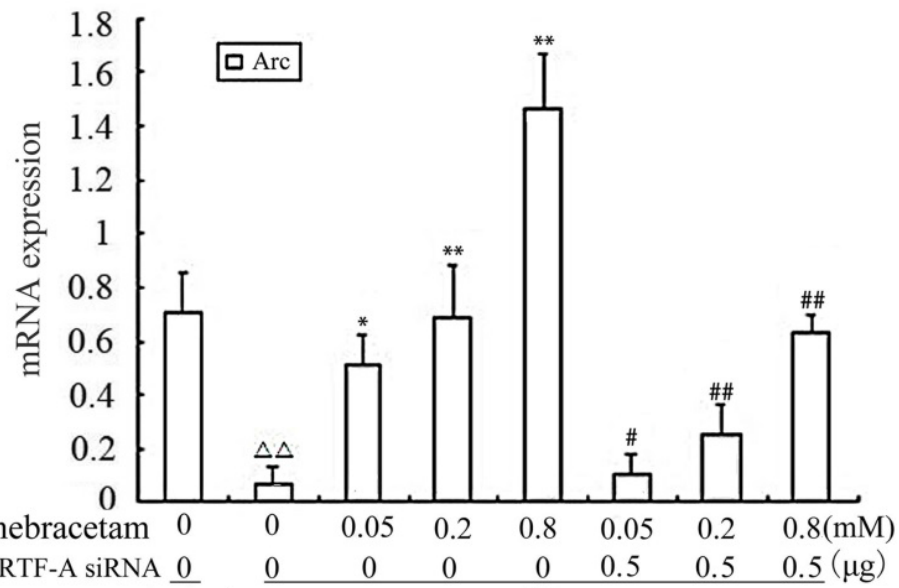

$\mathrm{D}$

Arc control

$\mathrm{A} \beta$

$\beta$-actin

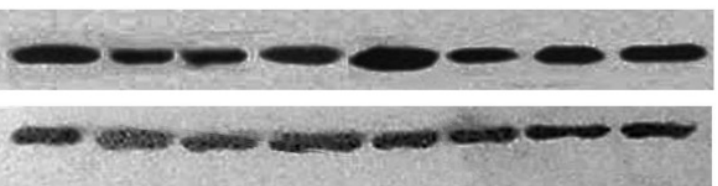

$\begin{array}{lllllllll}\text { nebracetam } & 0 & 0 & 0.05 & 0.2 & 0.8 & 0.05 & 0.2 & 0.8(\mathrm{mM})\end{array}$ $\begin{array}{llllllll}\text { MRTF-A siRNA } \underline{0} \quad \underline{0} & 0 & 0 & 0 & 0.5 & 0.5 & 0.5\end{array}(\mu \mathrm{g})$ control

$\mathrm{A} \beta$

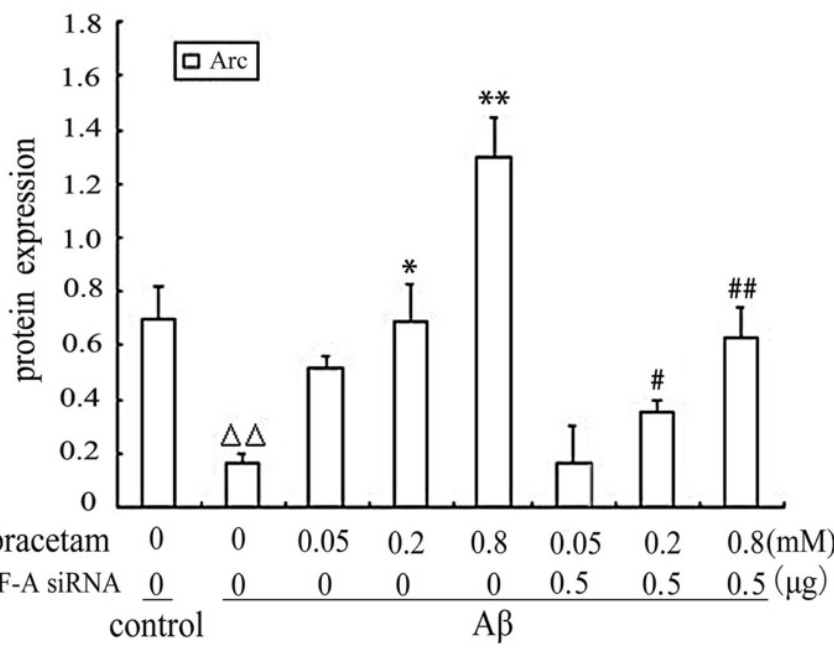

Figure 4: The regulation on the mRNA and protein levels of Mcl-1, Bcl-2 and Arc by nebracetam involved MRTF-A. (A, B) RT-PCR analysis for Mcl-1, Bcl-2 and Arc in hippocampus neurons. (C, D) Western blot analysis for the expressions of $\mathrm{Mcl}-1, \mathrm{Bcl}-2$ and $\mathrm{Arc}$ in hippocampus neurons. Results are presented as means $\pm \mathrm{S}$. $\mathrm{D}$ ( $\mathrm{n}=3$ ). ${ }^{\Delta} p<0.05$ or ${ }^{\Delta} p<0.01$ vs. Control, ${ }^{*} p<0.05$ or ${ }^{* *} p<0.01$ vs. model. ${ }^{\#} p<0.05$ or ${ }^{\#} p<0.01$ vs. the same dosage of nebracetam without MRTF-A siRNA groups, respectively.

Mcl-1, Bcl-2 and Arc expressions were determined by western blot. As shown in (Figure 6), Mcl-1, Bcl-2 and Arc expressions were decreased obviously by A $\beta 25-35$. However, preincubate with nebracetam upregulated the expressions of Mcl-1, Bcl-2 and Arc in a concentration manner $\left({ }^{*} \mathrm{p}<0.05\right.$ or $\left.{ }^{* *} \mathrm{p}<0.01\right)$. while at the presence of PD98059, the expression of Mcl-1, Bcl-2 and Arc was slightly lower than those in 
A

Mcl-1, Bcl-2, Arc

\&MRTF-A siRNA nebracetam A $\quad$ luc activity

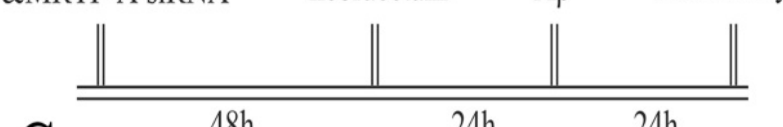

U
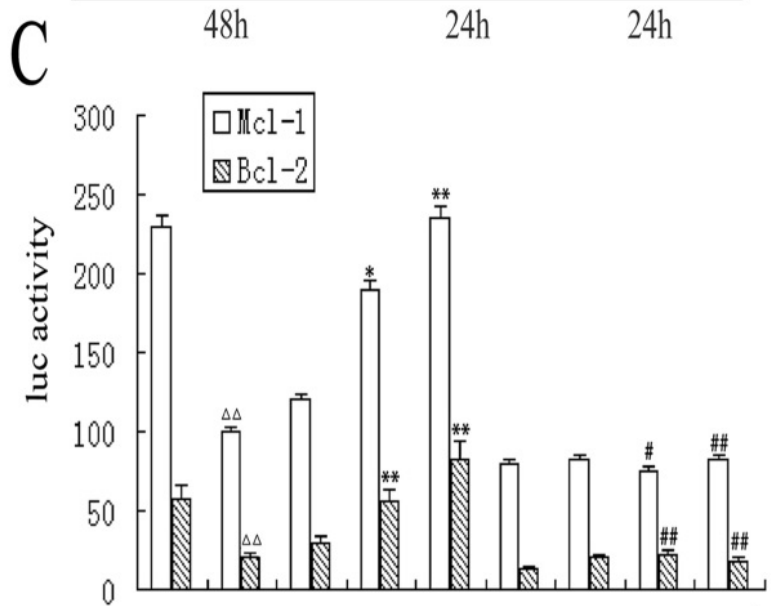

$\begin{array}{llllllllll}\text { nebracetam } & 0 & 0 & 0.02 & 0.5 & 0.8 & 0 & 0.02 & 0.5 & 0.8(\mathrm{mM})\end{array}$ MRTF-A siRNA $\underset{\text { control }}{0}$\begin{tabular}{lllllllll}
0 & 0 & 0 & 0 & 0.5 & 0.5 & 0.5 & 0.5 & $(\mathrm{ug})$ \\
\cline { 3 - 3 }
\end{tabular}

D<smiles>[13CH2][131I-]</smiles>

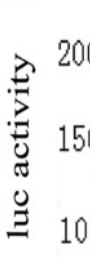<smiles>[CH-]1C2CCC1C2</smiles>

\section{$\square$ Arc}<smiles>C1CCCCC1</smiles><smiles>[13CH3][13CH3]</smiles><smiles>C1CCCCC1</smiles>$$
\text { a }
$$

0

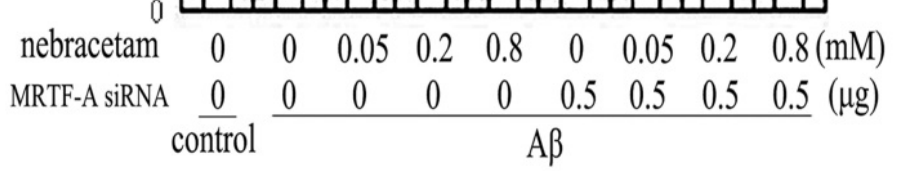

\section{B}
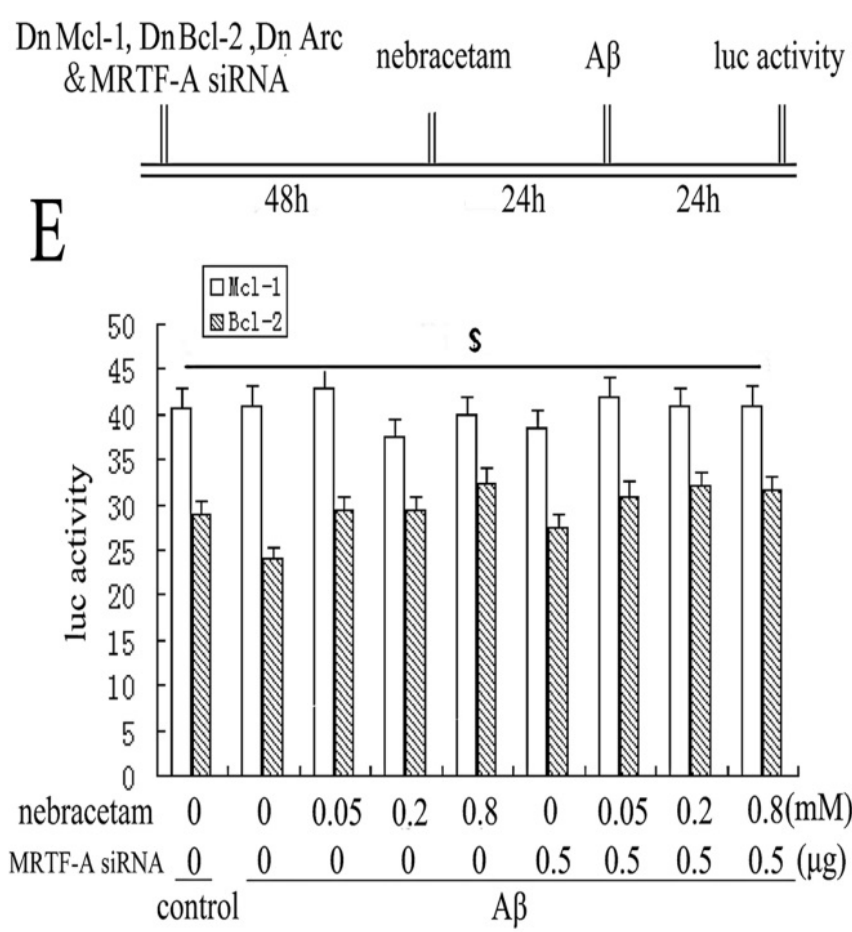

F

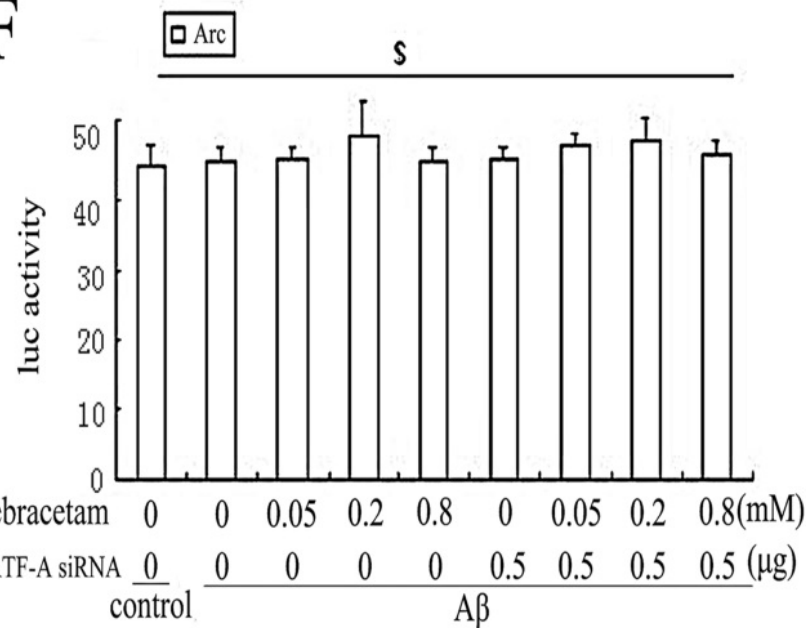

Figure 5: Upregulation of the transcription activity of $\mathrm{Mcl}-1, \mathrm{Bcl}-2$ and Arc in hippocampus neurons by nebracetam via a MRTF-A-dependent mechanism. (A, B) Flow chart for time points during cell processing. (C, D) The effect of co-transfection of MRTF-A siRNA on nebracetam enhanced the transactivity of Mcl-1, Bcl-2 and Arc promoters. (E, F) The effect of nebracetam on the transactivity of the dominant negative luciferase reporter vectors of Mcl-1 and Bcl-2 gene promoter. Results are presented as mean \pm S.D (n=3). ${ }^{\Delta} p<0.05$ or ${ }^{\Delta} p<<0.01$ vs. Control, ${ }^{*} p<0.05$ or ${ }^{* *} p<0.01$ vs. model. ${ }^{\#} p<0.05$ or ${ }^{\# \#} p<0.01$ vs. the same dosage of nebracetam without MRTF-A siRNA groups, respectively. \$: no significantly difference.

control group. As for the cells were co-treated nebracetam $(0.05 \mathrm{mM}$, $0.2 \mathrm{mM}, 0.8 \mathrm{mM}$ ) with PD98059, the increasing effect of nebracetam on Mcl-1, Bcl-2 and Arc expression was inhibited (\#p<0.05 or \#\#p<0.01).

\section{Discussion}

$\beta$-amyloid protein $(\mathrm{A} \beta)$ accumulation has been implicated as one of the most important pathogenic traits of Alzheimer's disease [21]. Evidence in vivo and vitro experiments showed that $A \beta$ induced inflammatory response, oxidative stress, neuronal apoptosis, and modifying neuronal synapses resulting in neurodegeneration and cognitive dysfunctions [22]. In this study, hippocampus neurons injury induced by $\mathrm{A} \beta 25-35$ has been used as $\mathrm{AD}$ model to investigate the protective effects of nebracetam and its possible mechanism [23]. It was found that the average apoptotic rate was obviously increased after cells were treated with $A \beta 25-35$. Nebracetam inhibited apoptosis in hippocampus neurons exposed to $A \beta 25-35$ by flow cytometry. Confocal images indicated an increase in synaptic loss treated with 

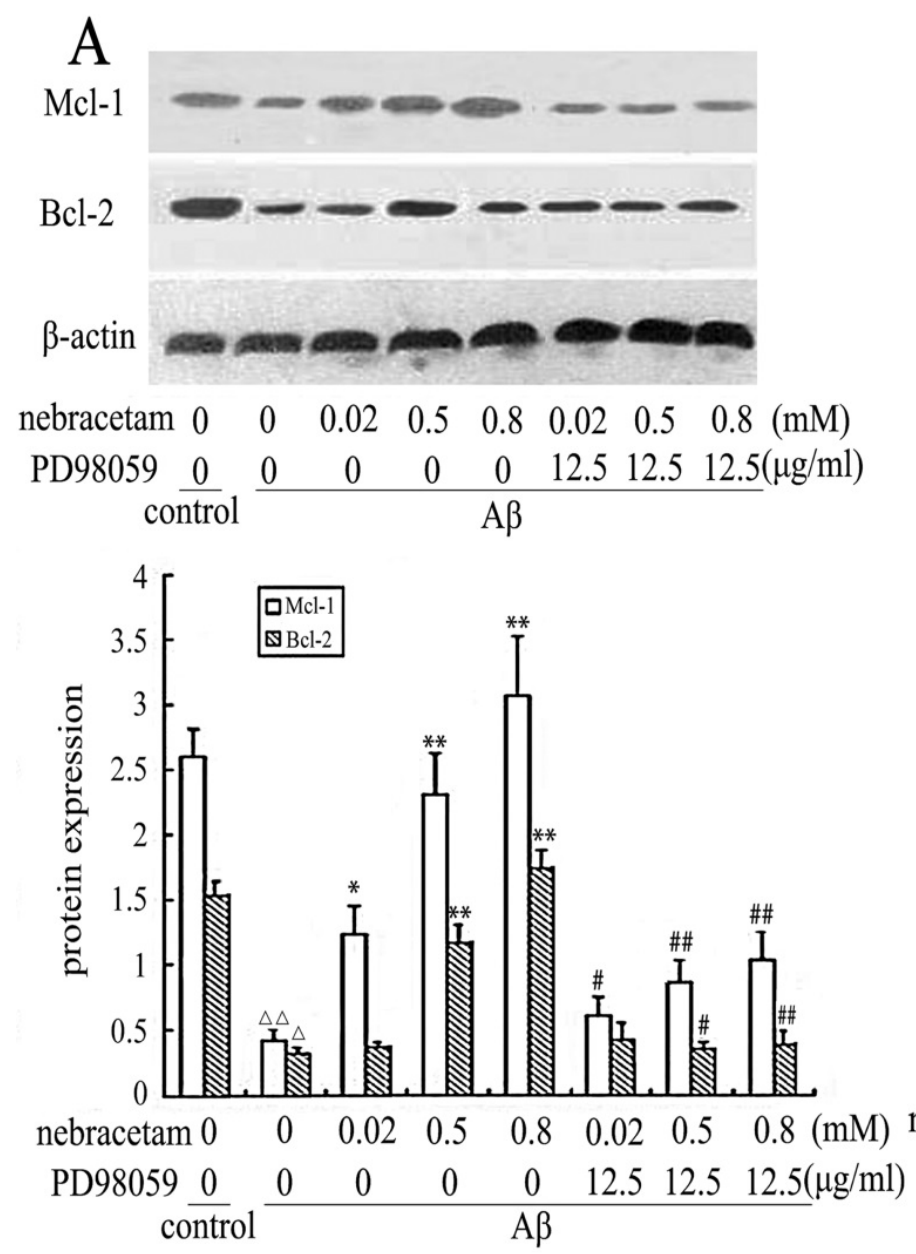

\section{$\mathrm{B}$}
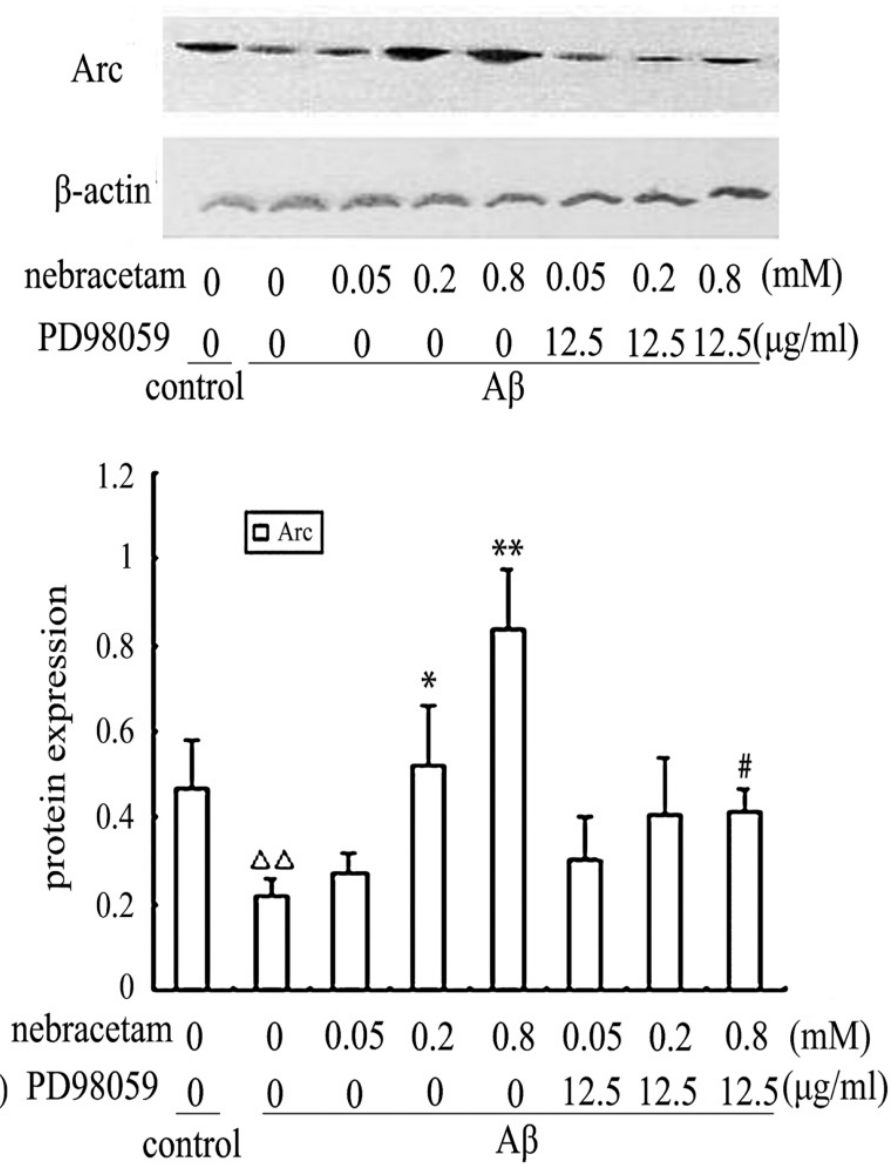

Figure 6: Nebracetam promoting MRTF-A-dependent anti-apoptotic on hippocampus neurons in ERK1/2-mediated manner. (A, B) The cells were transfected with PD98059 for $48 \mathrm{~h}$, the protein expression of $\mathrm{Mcl}-1, \mathrm{Bcl}-2$ and $\mathrm{Arc}$ in hippocampus neurons was analyzed by Western blot. Results are presented as means $\pm \mathrm{S}$.D $(n=5) .{ }^{\Delta} p<0.05$ or ${ }^{\Delta \Delta} p<0.01$ vs. Control, $" p<0.05$ or ${ }^{*} p<0.01$ vs. model. ${ }^{*} p<0.05$ or ${ }^{\# \#} p<0.01$ vs. the same dosage of nebracetam without $P D 98059$ groups, respectively.

A $325-35$, while nebracetam significantly suppressed synaptic loss induced by $\mathrm{A} \beta 25-35$ in a dose-dependent manner. Our experiment also demonstrated that the neuroprotection of nebracetam is related to enhancing the transactivity and protein expression of Mcl-1, Bcl-2 and Arc genes

MRTF-A, an important expressed transcription factor that plays an important role in cellular growth, and cardiac development, and mostly found in neurons such as cerebral cortex, hippocampus, etc. $[24,25]$, is a co-factor of SRF necessary for gene expression, plays a vital role in neuronal survival [26]. Previous studies have indicated that MRTF-A elevates SRF-driven transcription and enhances its stimulation by brain-derived neurotrophic factor (BDNF) in primary cortical neurons, which can regulate SRF and hence contributes to specific gene expression. In order to investigate nebracetam promoting expressions of Bcl-2, Mcl-1 and Arc involved MRTF-A manner, the cells were transfected with an expression plasmid for MRTF-A siRNA $(0.5 \mu \mathrm{g})$, the expressions of Mcl-1, Bcl-2 and Arc were determined by RT-PCR and Western blot. The results showed that the upregulation of Mcl-1, Bcl-2 and Arc expression by nebracetam were inhibited by MRTF-A siRNA, providing the evidence that MRTF-A was involved in the upregulation of Mcl-1, Bcl-2 and Arc expression by nebracetam.

How dose nebracetam upregulate expressions of Mcl-1, Bcl-2 and
Arc by MRTF-A manner? Several studies have showed that MRTF-A can regulate SRF through binding to it [27]. This complex actives target gene expression, requiring MRTF-A contacting a definite DNA sequence flanking the CArG box [28]. The promoter regions of Mcl-1, $\mathrm{Bcl}-2$ and Arc contained confirmed transcription factor binding sites including the CArG box [CC (A/T) 6GG] DNA sequences. In order to investigate whether nebracetam promoting expressions of Mcl-1, Bcl-2 and Arc is correlated to MRTF-A enhancing CArG box of their promoters, we cloned fragments of murine Mcl-1, Bcl-2 and Arc gene whose promoter contains the CArG box and their mutant in the site of CArG box. The results showed that MRTF-A siRNA inhibited the upregulation of nebracetam on the transcription activities of Mcl-1, Bcl-2 and Arc genes. On the other hand, it showed no significantly difference on these luciferase reporter gene activities at the presence of these gene mutants. Our data strongly confirmed the above hypothesis that the up-regulation of Mcl-1, Bcl-2 and Arc expression by nebracetam is correlated to MRTF-A enhancing CArG box in their promoters.

ERK1/2 as an important approach to $\mathrm{AD}$, the pathway is being widely studied [29-32]. Previous studies have demonstrated that this pathway can be involved in the regulation of synaptic structure and function [31,33]. Activation of ERK1/2 pathway plays a key role in the regulation of functional and structural synaptic plasticity [34]. It is hypothesized that the upregulation of nebracetam on Mcl-1, Bcl- 
2 and Arc modulation may mediated through ERK1/2 pathway. To determine whether nebracetam mediates its protective effect against A $225-35$-induced neurotoxicity in hippocampus neurons through the activation of the ERK1/2 pathway, we tested the influence of the ERK1/2 pathway inhibitor, PD98059. The result showed that upregulation of Mcl-1, Bcl-2 and Arc expressions in nebracetam-treated group was inhibited by PD98059, which suggested that the effect of nebracetam on hippocampus neurons injury induced by A $\beta 25-35$ through ERK1/2 signal pathway.

In short, our study described that nebracetam prevent hippocampus neurons injury induced by $A \beta 25-35$ via the mechanisms of inhibiting apoptosis and promoting synaptic plasticity via MRTF-A-mediated transactivation in ERK1/2-dependent pathway. The results showed that nebracetam could directly prevent the apoptosis of hippocampus neurons and the loss of synaptic plasticity by up regulating of Mcl-1, $\mathrm{Bcl}-2$ and Arc expressions. Furthermore, the expressions of Mcl-1, Bcl2 , and Arc genes regulated by nebracetam were correlated to MRTF-A manner which may be related to its triggering on the CArG box of their promoters. Meanwhile, these neuroprotective effects were associated with ERK1/2 signaling pathway.

\section{Acknowledgements}

Thanks are due to the Drug research base of cardiovascular and cerebral vascular in Wuhan University of Science and Technology for their financial support This work also was supported by the National Natural Science Foundation of China (NO. 31171327)

\section{References}

1. Kitamura Y, Kaneda T, Nomura Y (1991) Effects of nebracetam (WEB 1881 FU), a novel nootropic, as a M1-muscarinic agonist. Jpn J Pharmacol 55: 177180.

2. Shorvon S (2001) Pyrrolidone derivatives. Lancet 358: 1885-1892.

3. Quintanilla RA, Muñoz FJ, Metcalfe MJ, Hitschfeld M, Olivares G, et al. (2005) Trolox and 17beta-estradiol protect against amyloid beta-peptide neurotoxicity by a mechanism that involves modulation of the Wnt signaling pathway. J Bio Chem 280: 11615-11625.

4. Chrissobolis S, Miller AA, Drummond GR, Kemp-Harper BK, Sobey CG (2011) Oxidative stress and endothelial dysfunction in cerebrovascular disease. Front Biosci (Landmark Ed) 16: 1733-1745.

5. Caldwell CC, Yao J, Brinton RD (2015) Targeting the prodromal stage of Alzheimer's disease: bioenergetic and mitochondrial opportunities. Neurotherapeutics 12: 66-80

6. Pinto M, Moraes CT2 (2014) Mitochondrial genome changes and neurodegenerative diseases. Biochim Biophys Acta 1842: 1198-1207.

7. Yamaguchi H, Yamazaki T, Lemere CA, Frosch MP, Selkoe DJ (1992). Beta amyloid is focally deposited within the outer basement membrane in the amyloid angiopathy of Alzheimer's disease. An immunoelectron microscopic study. Am J Pathol; 141(1):249-59.

8. Brünner YF, Benedict C, Freiherr J (2013) [Targeting the brain through the nose. Effects of intranasally administered insulin]. Nervenarzt 84: 949-954

9. Ari C, Borysov SI, Wu J, Padmanabhan J, Potter H (2014) Alzheimer amyloid beta inhibition of Eg5/kinesin 5 reduces neurotrophin and/or transmitter receptor function. Neurobiol Aging 35: 1839-1849.

10. Smith IF, Green KN, LaFerla FM (2005) Calcium dysregulation in Alzheimer's disease: recent advances gained from genetically modified animals. Cell Calcium 38: 427-437.

11. Hsiung GY, Sadovnick AD (2007) Genetics and dementia: risk factors diagnosis, and management. Alzheimers Dement 3: 418-427.

12. Hardwick JM, Chen YB, Jonas EA (2012) Multipolar functions of BCL-2 proteins link energetics to apoptosis. Trends Cell Biol 22: 318-328.

13. Plath N, Ohana O, Dammermann B, Errington ML, Schmitz D, et al. (2006) Arc/ Arg3.1 is essential for the consolidation of synaptic plasticity and memories. Neuron 52: 437-444.
14. Miano JM (2003) Serum response factor: toggling between disparate programs of gene expression. J Mol Cell Cardiol 35: 577-593.

15. Posern G, Treisman R (2006) Actin' together: serum response factor, its cofactors and the link to signal transduction. Trends Cell Biol 16: 588-596.

16. Yu RX, Hu XM, Xu SQ, Jiang ZJ, Yang W (2011) Effects of fucoxanthin on proliferation and apoptosis in human gastric adenocarcinoma MGC-803 cells via JAK/STAT signal pathway. Eur J Pharmacol 657: 10-19.

17. Cao XL, Hu XM, Hu JQ, Zheng WX (2011). Myocardin-related transcription factor-A promoting neuronal survival against apoptosis induced by hypoxia/ ischemia. Brain Res; 1385:263-74.

18. Shirao T, Sekino $Y$ (2001) Clustering and anchoring mechanisms of molecular constituents of postsynaptic scaffolds in dendritic spines. Neurosci Res 40: 1-7.

19. Hayashi K, Ishikawa R, Ye LH, He XL, Takata K, et al. (1996) Modulatory role of drebrin on the cytoskeleton within dendritic spines in the rat cerebral cortex. J Neurosci 16: 7161-7170.

20. Kobayashi S, Shirao T, Sasaki T (2001) Drebrin expression is increased in spinal motoneurons of rats after axotomy. Neurosci Lett 311: 165-168.

21. Liu T, Jin H, Sun QR, Xu JH, Hu HT (2010) Neuroprotective effects of emodin in rat cortical neurons against beta-amyloid-induced neurotoxicity. Brain Res 1347: $149-160$.

22. McGeer PL, McGeer EG (2013) The amyloid cascade-inflammatory hypothesis of Alzheimer disease: implications for therapy. Acta Neuropathol 126: 479-497.

23. Sun L, Guo C, Wang T, Li X, Li G, et al. (2014) LIMK1 is involved in the protective effects of bone morphogenetic protein 6 against amyloid- $\left.\right|^{2}$-induced neurotoxicity in rat hippocampal neurons. J Alzheimers Dis 42: 543-554

24. Cen B, Selvaraj A, Burgess RC, Hitzler JK, Ma Z, Morris SW, et al.(2003) Megakaryoblastic leukemia 1, a potent transcriptional coactivator for serum response factor (SRF), is required for serum induction of SRF target genes. Mol Cell Biol; 23(18):6597-608.

25. Kalita K, Kharebava G, Zheng JJ, Hetman M (2006) Role of megakaryoblastic acute leukemia-1 in ERK1/2-dependent stimulation of serum response factordriven transcription by BDNF or increased synaptic activity. J Neurosci 26 : 10020-10032.

26. Li CL, Sathyamurthy A, Oldenborg A, Tank D, Ramanan N (2014) SRF phosphorylation by glycogen synthase kinase-3 promotes axon growth in hippocampal neurons. J Neurosci 34: 4027-4042.

27. Vartiainen MK, Guettler S, Larijani B, Treisman R (2007) Nuclear actin regulates dynamic subcellular localization and activity of the SRF cofactor MAL. Science 316: 1749-1752.

28. Zaromytidou Al, Miralles F, Treisman R (2006) MAL and ternary complex factor use different mechanisms to contact a common surface on the serum response factor DNA-binding domain. Mol Cell Biol 26: 4134-4148.

29. Rezai-Zadeh K, Shytle D, Sun N, Mori T, Hou H, Jeanniton D, et al.(2005) Green tea epigallocatechin-3-gallate (EGCG) modulates amyloid precurso protein cleavage and reduces cerebral amyloidosis in Alzheimer transgenic mice. J Neurosci 25: 8807-8814.

30. Shi C, Wu F, Xu J, Zou J (2011) Bilobalide regulates soluble amyloid precurso protein release via phosphatidyl inositol 3 kinase-dependent pathway. Neurochem Int 59: 59-64.

31. Shi C, Zheng DD, Wu FM, Liu J, Xu J (2012). The phosphatidyl inositol 3 kinase-glycogen synthase kinase 3beta pathway mediates bilobalide-induced reduction in amyloid beta-peptide. Neurochem Res 37: 298-306.

32. Shi C, Zhu X, Wang J, Long D (2014) Estrogen receptor Ît promotes nonamyloidogenic processing of platelet amyloid precursor protein via the MAPK ERK pathway. J Steroid Biochem Mol Biol 144 Pt B: 280-285.

33. Thomas CG, Miller AJ, Westbrook GL (2006) Synaptic and extrasynaptic NMDA receptor NR2 subunits in cultured hippocampal neurons. J Neurophysiol 95: 1727-1734.

34. Thomas GM, Huganir RL (2004) MAPK cascade signalling and synaptic plasticity. Nat Rev Neurosci 5: 173-183. 